\title{
Prenatal testosterone and dihydrotestosterone exposure disrupts ovine testicular development
}

\author{
Charles L Bormann ${ }^{1,5}$, Gary D Smith ${ }^{1,2,3,5}$, Vasantha Padmanabhan ${ }^{1,2,4,5}$ and Theresa M Lee ${ }^{5,6}$ \\ Departments of ${ }^{1}$ Obstetrics and Gynecology, ${ }^{2}$ Molecular and Integrative Physiology, ${ }^{3}$ Urology, ${ }^{4}$ Pediatrics, \\ ${ }^{5}$ Reproductive Sciences Program and ${ }^{6}$ Psychology, University of Michigan, Ann Arbor, Michigan 48109, USA
}

Correspondence should be addressed to T M Lee at LS\&A Psychology and Neuroscience Program, University of Michigan, Psychology 525 E University \#4030-1109, Ann Arbor, Michigan 48109, USA; Email: terrilee@umich.edu

\begin{abstract}
Androgens play important roles during the first trimester of intrauterine life, coinciding with genital tract differentiation, during virilization and maintenance of secondary male characteristics, and during initiation of spermatogenesis. Little is known about the impact of inappropriate exposure to excess androgens during fetal development on male sexual maturation and reproduction. The objectives of this study were to determine the effects of prenatal $5 \alpha$-dihydrotestosterone (DHT) and testosterone treatment during ovine sexual differentiation on post-pubertal testicular formation and subsequent potential for fertility as assessed by epididymal sperm characteristics. Rams prenatally treated with testosterone exhibited increased testicular weight relative to age-matched controls and prenatal DHT-treated rams $(\boldsymbol{P}<\mathbf{0 . 0 5})$, as well as elevated total and free testosterone concentrations compared with DHT-treated rams $(\boldsymbol{P}=\mathbf{0 . 0 7}$ and $\boldsymbol{P}<\mathbf{0 . 0 5}$ respectively). The percentage of progressively motile sperm from the epididymis was significantly reduced in prenatal DHT-treated but not testosterone-treated rams compared with control rams $(P<0.05)$. The testosterone-treated rams had a greater number of germ cell layers than DHT-treated rams, but comparable to the controls. Prenatal testosterone-treated rams had significantly larger seminiferous tubule diameter and lumen diameter compared with prenatal DHT-treated $(P<0.05)$. Significantly, more prenatal DHT- and testosterone-treated rams $(P<0.05)$ had occluded tubule lumen than control rams. Findings from this study demonstrate that exposure to excess testosterone/DHT during male fetal sexual differentiation have differential effects on post-pubertal testicular size, seminiferous tubule size and function, sperm motility, and testosterone concentrations.

Reproduction (2011) 142 167-173
\end{abstract}

\section{Introduction}

Estradiol and testosterone, two important gonadal steroid hormones, mediate growth, maintenance, and function of many reproductive tissues and regulate ovarian follicular development and spermatogenesis. The importance of steroid hormones for normal reproductive function is convincingly shown in knockout rodent models (Eddy et al. 1996, Couse \& Korach 1999, Robertson et al. 1999, Curtis \& Korach 2000, Hewitt \& Korach 2003, Matsumoto et al. 2005). For instance, both estrogen receptor knockout females and males are infertile with females demonstrating hypoplastic uteri and hyperemic ovaries and males showing atrophy of the testes and seminiferous tubule dysmorphogenesis (Eddy et al. 1996).

Inappropriate steroid receptor signaling relative to timing, duration, and level of exposure to androgens culminate in dysfunctions at various levels. For instance, testosterone emanating from male littermates sharing the same uterine horn leads to masculinization of female rats (Meisel \& Ward 1981). Several studies have also documented that inappropriate exposure to testosterone during development culminates in phenotypic, reproductive, and behavioral anomalies in female offspring of many species (rat (Wolf et al. 2002); mouse (Ryan \& Vandenbergh 2002); guinea pig (Resko \& Roselli 1997); sheep (Padmanabhan et al. 2006, Steckler et al. 2007, Recabarren et al. 2008); and monkey (Abbott et al. 1998, Dumesic et al. 2005)). Congenital adrenal hyperplasia in humans, an autosomal recessive disease resulting from 21-hydroxylase deficiency, leads to excess androgen exposure during fetal development with females born with virilized external genitalia (Forest et al. 2004), similar to the effects caused by experimental treatments in animal models.

Although extensive characterization of females has been undertaken following prenatal exposure to excess testosterone, such in-depth studies in male offspring are limited. Testosterone and dihydrotestosterone (DHT), one of the metabolites of testosterone, have specific roles during male sexual differentiation. Testosterone is directly involved in the development and differentiation of Wolffian duct-derived structures (epididymides, vas 
deferens, seminal vesicles, and ejaculatory ducts), and $\mathrm{DHT}$ is the active ligand in a number of androgen target tissues, including the urogenital sinus and tubercle (Wilson et al. 1993, Randall 1994). Recent studies in sheep have found that exposure to excess testosterone from days 30 to 90 of gestation leads to increased anogenital ratio (Manikkam et al. 2004) and reduced sperm count and motility in the male offspring (Recabarren et al. 2008). This study expands these initial observations to determine whether exposure to excess androgens during ram sexual differentiation disrupted testicular formation and sperm characteristics. As testosterone can be aromatized to estrogen, these studies compared prenatal exposure with excess testosterone with DHT (non-aromatizable androgen) to distinguish androgenic contribution from estrogenic contribution.

\section{Results}

At the time of study, bodyweights of control, prenatal testosterone, and DHT-treated males did not differ from each other (Table 1). Free testosterone concentration and testes mass were greater $(P<0.05)$ in testosteronetreated rams than DHT-treated rams, but neither group differed from controls (Table 1). Total testosterone concentrations were higher than free testosterone and consistent with the free testosterone concentrations (Table 1), but did not significantly differ among groups, in part because of the greater variation among individuals. However, a non-parametric test (because of group differences in variation) detected a trend toward a difference between the DHT-treated and the testosterone-treated rams (Dwass-Steel-Critchlow-Fligner test $=3.098, P=0.07)$. In addition, there were no differences in penis length between treatments (Table 1).

Epididymal sperm motility was significantly reduced in prenatal DHT-treated rams $(P<0.05)$ but not in testosterone-treated males compared with control males (Table 2). There were no differences in percentage of sperm exhibiting normal morphology or in the percentage of live/dead sperm among the three treatment groups (Table 2).

Seminiferous tubule diameters of prenatal testosterone-treated rams tended to be larger than the controls but did not achieve statistical significance. Prenatal

Table 1 Bodyweights, free testosterone levels, penis length, and testicular weight from 9-month-old Suffolk rams prenatally treated with testosterone and $5 \alpha$-dihydrotestosterone (DHT).

\begin{tabular}{lcccc}
\hline Treatment & $\begin{array}{c}\text { Bodyweight } \\
(\mathrm{kg})\end{array}$ & $\begin{array}{c}\text { Testosterone } \\
(\mathrm{pg} / \mathrm{ml})\end{array}$ & $\begin{array}{c}\text { Penis length } \\
(\mathrm{cm})\end{array}$ & $\begin{array}{c}\text { Paired testes } \\
\text { weight }(\mathrm{g})\end{array}$ \\
\hline Control & $52.03 \pm 2.28^{*}$ & $1.18 \pm 0.39^{*,+}$ & $28.00 \pm 1.91^{*}$ & $287.2 \pm 19.0^{*},+$ \\
Testosterone & $52.57 \pm 1.78^{*}$ & $1.68 \pm 0.69^{\dagger}$ & $27.33 \pm 1.63^{*}$ & $330.1 \pm 25.5^{+}$ \\
DHT & $53.06 \pm 1.58^{*}$ & $0.63 \pm 0.19^{*}$ & $28.80 \pm 4.09^{*}$ & $258.4 \pm 10.2^{*}$
\end{tabular}

Values are expressed as mean \pm s.E.M. ${ }^{*}{ }^{\dagger}$ Statistical significance

between treatments, $P<0.05$.
Table 2 Motility, morphology, and percentage of live sperm collected from the caudal epididymis of 9-month-old Suffolk rams prenatally treated with testosterone and $5 \alpha$-dihydrotestosterone (DHT).

\begin{tabular}{lccc}
\hline Treatment & Motility $(\%)$ & $\begin{array}{c}\text { Normal sperm } \\
\text { morphology }(\%)\end{array}$ & Live sperm $(\%)$ \\
\hline Control & $32.29 \pm 14.0^{+}$ & $72.14 \pm 13.8^{*}$ & $51.14 \pm 8.8^{*}$ \\
Testosterone & $22.17 \pm 10.7^{+}$ & $69.33 \pm 12.2^{*}$ & $48.17 \pm 10.7^{*}$ \\
DHT & $6.20 \pm 1.6^{*}$ & $69.40 \pm 8.1^{*}$ & $34.20 \pm 7.3^{*}$ \\
\hline
\end{tabular}

Values are expressed as mean \pm s.E.M. ${ }^{*}{ }^{\dagger}$ Statistical significance between treatments, $P<0.05$.

DHT-treated ram seminiferous tubule diameters were significantly smaller than prenatal testosterone-treated rams $(P<0.05)$ but similar to that of controls (Table 3$)$. The seminiferous tubule lumen diameter of prenatal testosterone-treated males was significantly larger than that of control and prenatal DHT-treated males $(P<0.05)$. There were no differences in the number of cell layers of the basal and adluminal compartment between control and prenatal testosterone-treated males; however, there was a reduction in cell layers in DHT-treated males compared with the other two groups $(P<0.05 ;$ Table 3$)$. Significantly more prenatal DHT- and testosterone-treated rams had closed seminiferous tubule lumina than control males $(P<0.05 ;$ Fig. 1$)$.

\section{Discussion}

Androgens play an important role in organization, development, and function of many reproductive tissues and other biological processes. Results from this study demonstrate that increased androgen exposure during male fetal sexual differentiation (gestational days 30-90) altered testicular size, free testosterone concentrations in male lambs, seminiferous tubule size and function, germ cell number, and sperm motility. The impact of testosterone and DHT differed for some measures. These differences may relate to degree of androgen exposure (DHT is a more potent androgen) or contribution from estradiol derived from aromatization of testosterone. Prenatal testosterone treatment elevates fetal testosterone levels similar to those seen in intact males (Veiga-Lopez et al. 2011). Together, these findings suggest that this increase in androgens during a critical period of development has a significant impact on seminiferous tubule formation and germ cell production, which could ultimately have negative effects on subsequent fertility.

The average number of cell layers from seminiferous tubule lumen to lamina propria was reduced in DHTtreated rams (Table 3). This decrease in cell layers likely results from a reduction in spermatocytes observed in this treatment group. Prenatal DHT-treated ram testes were significantly smaller than testosterone treated, which did not differ from control males. In most species, 
Table 3 Measurements of seminiferous tubules, seminiferous tubule lumina, and germ cell layers collected from 9-month-old Suffolk rams prenatally treated with testosterone and $5 \alpha$-dihydrotestosterone (DHT).

\begin{tabular}{lccc}
\hline Treatment & $\begin{array}{c}\text { Seminiferous } \\
\text { tubule diameter } \\
(\mu \mathrm{M})\end{array}$ & $\begin{array}{c}\text { Seminiferous } \\
\text { lumen diameter } \\
(\mu \mathrm{M})\end{array}$ & $\begin{array}{c}\text { Mean semini- } \\
\text { ferous tubule } \\
\text { germ cell layers }\end{array}$ \\
\hline Control & $342.46 \pm 5.55^{*,+}$ & $174.66 \pm 3.45^{*}$ & $3.87 \pm 0.11^{+}$ \\
Testosterone & $360.94 \pm 5.41^{+}$ & $211.44 \pm 6.13^{+}$ & $3.76 \pm 0.16^{+}$ \\
DHT & $310.36 \pm 6.19^{*}$ & $168.93 \pm 4.78^{*}$ & $3.18 \pm 0.11^{*}$ \\
\hline
\end{tabular}

Values are expressed as mean \pm s.E.M. ${ }^{*}{ }^{+}$Statistical significance between treatments, $P<0.05$.

testicular hypertrophy is associated with increased diameter and length of the seminiferous tubules (Voglmayr \& Mattner 1968, Boockfor et al. 1983, Kosco et al. 1989), increased numbers of germ and Sertoli cells (Waites et al. 1983, 1985, Hochereau-de Reviers et al. 1984, Orth 1984), and increased sperm production per testis at maturity (Voglmayr \& Mattner 1968, Barnes et al. 1980). The finding that DHT-treated ram testes were smaller is suggestive of reduced differentiation and proliferation.

A surprising finding in this study was a significant increase in percentage of seminiferous tubule lumens that were partially or completely occluded in DHT- and testosterone-treated rams. Although it is unclear why these lumens are blocked, it is likely that occlusion would negatively affect fertility. After spermiogenesis, each sperm cell is released by Sertoli cells into the seminiferous tubule lumen by the process of spermiation. Sperm migrate along the tubule to the rete testis and into the caput epididymis. Spermatozoa released into the seminiferous tubule lumen are suspended in fluid produced primarily by Sertoli cells (Zaneveld 1978). Occlusion of seminiferous tubules blocks transport of sperm, thus decreasing the concentration of sperm in the ejaculate. This could in part explain the greatly reduced concentrations of sperm in ejaculates from adult rams whose mothers were prenatally treated with testosterone (Recabarren et al. 2008). Further studies are required to determine whether lumen blockage is due to increased apoptosis in seminiferous tubules or an inhibition of Sertoli cell function preventing fluid secretion and normal sperm transport within the seminiferous tubule lumen.

There were no morphological differences in mature sperm among the treatment groups indicating that prenatal androgen exposure does not affect the process of spermiogenesis. However, prenatal DHT-treated rams had significantly reduced percentage of forward progressing motile sperm compared with testosteronetreated and control rams. The lack of difference between control and testosterone-treated rams differ from the findings of Recabarren et al. (2008). In their study, there was a significant decrease in the straight-line velocity of sperm from rams whose mothers were treated with testosterone during gestation. The differences may relate to the duration of testosterone treatment. In Recabarren's study, pregnant mothers were treated with testosterone propionate from days 30 to 120 of pregnancy, 30 days longer than in the current study.

To a certain degree, some effects (i.e. sperm motility and seminiferous tubule germ cell layers) were more pronounced in DHT-treated males compared with testosterone-treated males. It is conceivable that such differences may be related to testosterone having a lower affinity than DHT for the androgen receptor and its dissociation from the receptor is five times faster than DHT or that the more pronounced differences observed between the two androgen treatments are a result of the higher binding affinity of DHT to the androgen receptor. These differences may also relate to how DHT and testosterone act locally and distally on androgen target tissues. DHT acts on distally located receptors of the urogenital sinus and tubercle. Testosterone plays a more significant role on locally located Wolffian duct-derived structures. In this study, rams were exposed to excess androgens, allowing both local and distal androgen receptors to be activated. To what extent aromatization of testosterone to estrogen plays a role in the differential effects exerted by prenatal treatment with testosterone and DHT is unclear. The mechanisms by which androgen exposure during male fetal development negatively affects reproductive function of mature rams remain to be elucidated.

$\mathrm{LH}$ and $\mathrm{FSH}$ were not measured in this experiment. However, Recabarren et al. (2007) have demonstrated that rams born to mothers exposed to excess testosterone produced less $\mathrm{LH}$ in response to GNRH agonist stimulation at 20 and 30 weeks of age. In addition,

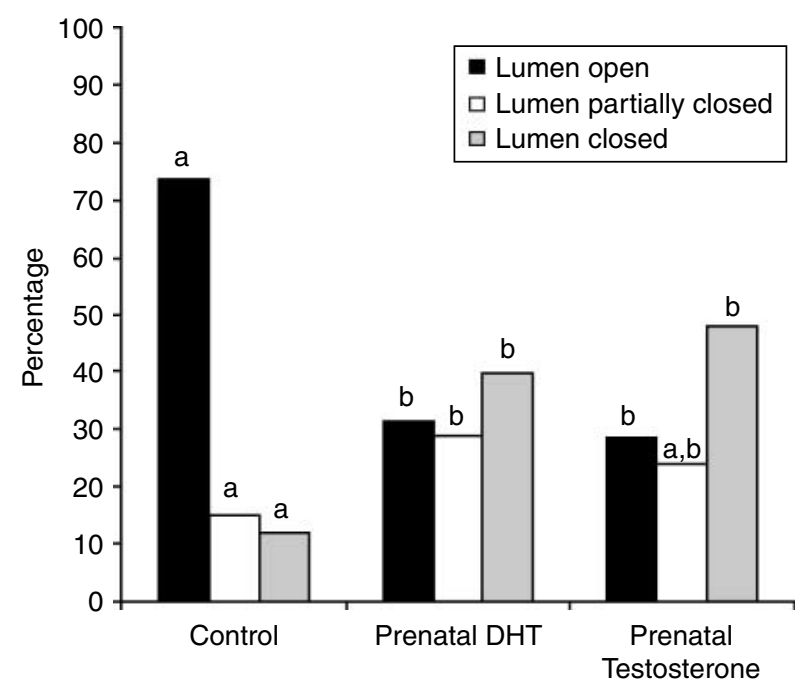

Figure 1 Percentage of opened, partially closed, and fully closed seminiferous tubule lumina from stages I-VI from 9-month-old Suffolk rams prenatally treated with testosterone and $\mathrm{DHT}$. ${ }^{\mathrm{a}, \mathrm{b}}$ Different superscripts between treatments indicate statistical significances within state of luminal opening, $P<0.05$. 

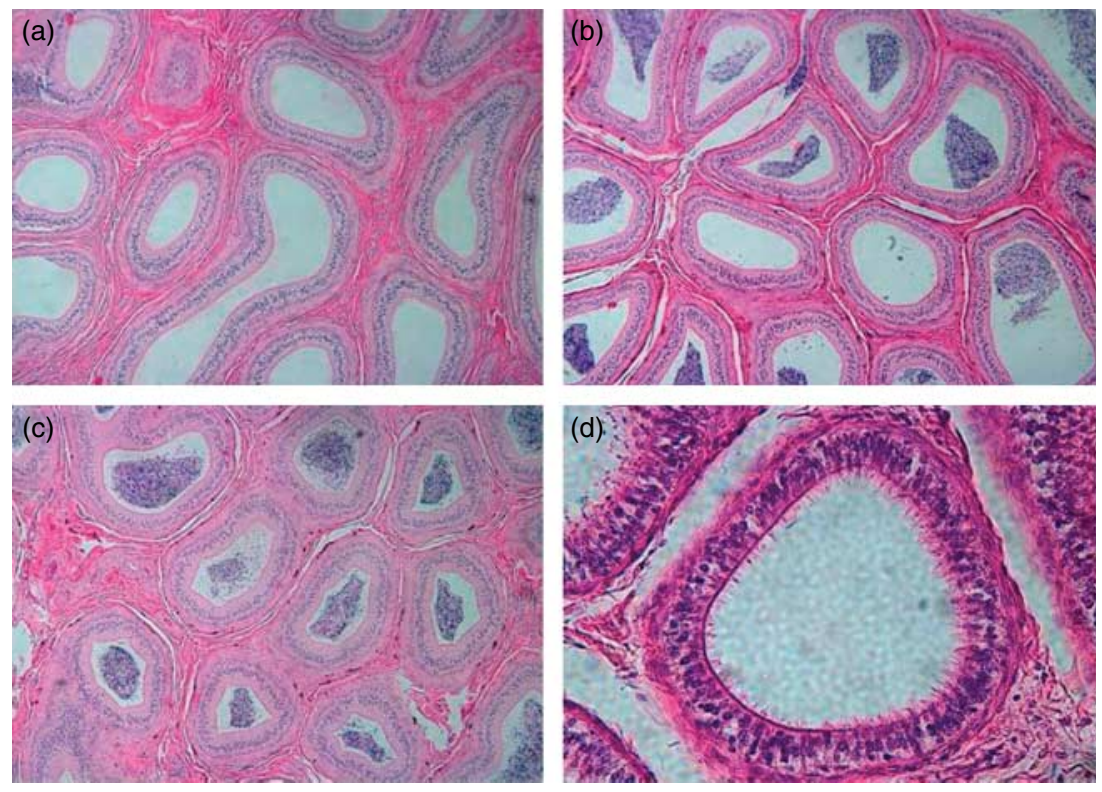

Figure 2 Representative images of (a) open, (b) partially closed, and (c) fully closed seminiferous tubule lumina from 9-month-old Suffolk rams prenatally treated with testosterone and DHT at $200 \times$ magnification. Image (d) represents an open seminiferous tubule lumen at $400 \times$ magnification. rams exposed to testosterone during development had significantly higher plasma testosterone levels than controls at 20 weeks of age but were at lower levels than controls at 30 weeks (Recabarren et al. 2007). This advancement in the developmental trajectory of gonadal testosterone responses to LH stimulation may account for the differences in free testosterone in male fetuses exposed to excess DHT and testosterone.

Many differences observed in androgen-treated rams were similar to pathologies of human males with GNRH/gonadotropin-based disorders (Davidson et al. 1983, Booth et al. 1987, Nachtigall et al. 1997, Cabrera et al. 2001, Stikkelbroeck et al. 2001). Whether the disruptive effects of prenatal testosterone treatment in testicular dynamics is the result of disrupted LH pulse characteristics as is the case with the female offspring (Masek et al. 1999, Sarma et al. 2005) remains to be ascertained.

In summary, findings from this study clearly demonstrate that prenatal testosterone and DHT treatment during male fetal sexual differentiation have differential effects on post-pubertal testicular size, seminiferous tubule size and function, and progressive sperm motility. The occlusion of the seminiferous tubule lumens and reduction in progressive sperm movement may greatly compromise the fertility of male offspring exposed to high androgens during critical periods of gestation.

\section{Materials and Methods}

\section{Prenatal androgen treatment}

Suffolk ewes were brought to the Sheep Research Facility at the University of Michigan for timed artificial insemination with Suffolk semen and for subsequent androgen treatment.
All animal procedures were approved by the University of Michigan Committee for Use and Care of Animals and were consistent with the National Institutes of Health Guide for Use and Care of Animals. Pregnant ewes were administered twice weekly i.m. injections of $100 \mathrm{mg}$ testosterone-propionate (Sigma-Aldrich Corp.) or $100 \mathrm{mg}$ DHT propionate in $2.4 \mathrm{ml}$ cottonseed oil (Sigma-Aldrich Corp.) from 30 to 90 days of gestation (term $=147$ days). Days 30-90 were selected for treatment, as this is the period of sexual differentiation in sheep. Control ewes received an equal volume of vehicle. Prenatal testosterone treatment elevates testosterone levels in female fetuses from near detection level in controls to levels seen in male fetuses at 65 days of gestation (Veiga-Lopez et al. 2011). Lambs were all born in mid-March. The concentrations of testosterone and DHT chosen resulted in similar anogenital ratios in the female offspring. At birth, males were distinguished from prenatal testosterone- and DHT-treated females by palpating the scrotal sac to determine the presence of testes.

A total of seven control, six testosterone, and five DHTtreated rams were weaned at 8 weeks of age and vasectomized at 14 weeks to prevent unwanted pregnancies in the flock. The 18 rams were obtained from 18 different mothers, some were singletons, whereas the remaining had either a male or a female sibling. The males obtained from male twin pairs were chosen at random. All rams had access to water, alfalfa pellets, and hay ad libitum for the first 4 months of life, after which they had access only to hay and water. Males were reared in a mixed sex, same age group until 6 months of age, when they were moved to pasture with a group of older, intact ewes $(N=50)$. When the breeding season began for pasture ewes in late September, these young vasectomized males had access to them, and all engaged in copulatory behavior when they had access to an estrous female. 


\section{Vasectomy}

Males were anesthetized initially using ketamine hydrochloride (4-6 mg/kg, i.v.) and diazepam (0.2-0.3 mg/kg, i.v.). Once this anesthetic had taken effect, the animal was intubated and transported to a surgical table where it was secured in a supine position. Anesthesia was maintained with a mixture of halothane gas $(\sim 1.5 \%)$ in nitrous oxide $(1 / 3)$ and oxygen $(2 / 3)$. After clipping the wool on the dorsal aspect of the scrotum and adjacent abdomen, the skin was prepared for surgery by standard surgical scrub and draped with sterile surgical drape. An incision was made on one side of the scrotum and the subcutaneous tissue dissected to expose the blood vessels of the pampiniform plexus, which contains the testicular artery and vein. The vas deferens was palpated as a muscular tube, elevated, and dissected free from the surrounding vasculature. After ligating both ends of the section of vas deferens to be removed, to ensure that the tube is tied shut, a 4-5 cm segment of vas deferens was cut out. Subcutaneous tissue was then closed with an interrupted cross-stitch and the skin closed separately with an interrupted cross-stitch. The suture material used for both closures was \#1 chromic gut. The procedure was then repeated on the other side such that the vas deferens was bilaterally interrupted.

\section{Testosterone measurement}

Due to limitations in resources, rams were killed in midDecember, during the breeding season. Prior to killing, rams were weighed, blood was collected via jugular venipuncture into heparinized tubes, and total testosterone (Modified version of Siemens Coat-a-Count testosterone assay; intra-assay coefficient of variation was $7.4 \%$ ) and free testosterone (MP Biomedicals, Orangeburg, NY, USA; intra-assay coefficient of variation was $5.2 \%$ ) were measured. The minimum detectability of the free testosterone assay was $0.18 \mathrm{pg} / \mathrm{ml}$ and for the total testosterone assay was $2 \mathrm{ng} / \mathrm{dl}$.

\section{Testicular biometry}

Testes were collected immediately after killing (overdose by i.v. injection of FatalPlus that contains sodium pentobarbital) of the 8.5- to 9-month-old rams. Testicles were weighed in pairs. Penis length was measured from the base to the tip of the glans penis.

\section{Histological evaluation}

Approximately, $0.5 \mathrm{~mm}$ sections of tissue from testis were fixed in 10\% neutral-buffered formalin (Protocol, Middletown, VA, USA) for $24 \mathrm{~h}$ and then washed in $70 \%$ ethanol. Tissue was dehydrated in alcohol and embedded in paraffin wax. To avoid duplication of cell counts, two $5 \mu$ m-thick sections were cut at varying depths. Slides were stained with hematoxylin and eosin (H\&E). We selected five round seminiferous tubules from stages I-VI of spermatogenic wave per cross section (ten round seminiferous tubules per ram) for analysis. The number of cell layers of basal and adluminal compartment (lumen to lamina propria) was measured at $400 \times$ magnification. All histological evaluations were done by a single individual, in a random order without knowledge of treatment.

\section{Luminal measurements}

Sections $(5 \mu \mathrm{m}$ thick) from paraffin-embedded testes were prepared and stained with H\&E. Embedded tissues were cut at three different depths on three separate occasions to ensure that differences were not due to a fixation artifact. Approximately, 20 opened seminiferous tubule lumens from stages $\mathrm{I}-\mathrm{VI}$ from each ram were measured at $400 \times$ magnification using SPOT Imaging Solutions (Diagnostic Instruments, Inc., Sterling Heights, MI, USA). Luminal measurements were averaged between two separate measurements of each lumen. Measurements were averaged between a $180^{\circ}$ horizontal measurement of the lumen and a $180^{\circ}$ vertical measurement of the lumen. Measurements were made at a magnification of $400 \times$. In addition, the percentage of opened lumens, partially closed lumens, and fully closed lumens were calculated for each ram. Open lumens had a clear visible lumen with a well-defined perimeter and no debris. Partially closed lumens had a distinct perimeter and contained debris filling up to $50 \%$ of the lumen. Fully closed lumens had distinct perimeters and $>50 \%$ of the luminal space was filled with debris (Fig. 2).

\section{Sperm assessment}

Sperm were collected from caudal epididymides by cutting one end of the epididymis (between caudal and corpus) and repeatedly milking the epididymis into an empty dish. The volume collected from each male was not recorded. Sperm assessments were performed in a treatment-blinded fashion where motility, morphology, and live-dead sperm stains were counted twice and averaged for each ram. Sperm motility was assessed at the light microscope level at $100 \times$ magnification. Motility was recorded as a percentage of forward-progressing sperm cells. Sperm were diluted 20-fold in HEPES-buffered medium (Gibco) prior to analysis to allow for clear motility visualization. A nigrosin-eosin 'live-dead' stain was used to assess sperm morphology and to evaluate the integrity of the acrosome and sperm membrane.

\section{Statistical analyses}

Differences among treatment groups were tested with ANOVA. If there were statistically significant differences, then post hoc Tukey-Kramer multiple comparison method was used to look for specific differences between treatments. Differences were considered statistically significant at a level of $P<0.05$. Results are shown as mean \pm S.E.M.

\section{Declaration of interest}

The authors declare that there is no conflict of interest that could be perceived as prejudicing the impartiality of the research reported. 


\section{Funding}

This research was supported by USPHS grant P01-HD44232 (V Padmanabhan, T M Lee). Support for C L Bormann was provided by a NIH training grant in Reproductive Sciences and T32-HD07048 (G D Smith).

\section{Acknowledgements}

The authors would like to express our appreciation to the members of Dr V Padmanabhan's laboratory for their assistance with this study. We would also like to thank Eila Roberts and other members of Dr T M Lee and Dr G D Smith's laboratories for their assistance in tissue collection and processing. In addition, we would like to thank Rodney Dunn for assistance with statistical analyses.

\section{References}

Abbott DH, Dumesic DA, Eisner JR, Colman RJ \& Kemnitz JW 1998 Insights into the development of polycystic ovary syndrome (PCOS) from studies of prenatally androgenized female rhesus monkeys. Trends in Endocrinology and Metabolism 9 62-67. (doi:10.1016/S1043-2760 (98)00019-8)

Barnes MA, Longnecker JV, Riesen JW \& Woody CO 1980 Influence of unilateral castration and increased plane of nutrition on sexual development of Holstein bulls. III. Endocrine responses. Theriogenology 14 67-81. (doi:10.1016/0093-691X(80)90135-1)

Boockfor FR, Barnes MA \& Dickey JF 1983 Effects of unilateral castration and unilateral cryptorchidism of the Holstein bull on in vitro Leydig cell response. Journal of Animal Science 56 1386-1392.

Booth JD, Merriam GR, Clark RV, Loriaux DL \& Sherins RJ 1987 Evidence for Leydig cell dysfunction in infertile men with a selective increase in plasma follicle-stimulating hormone. Journal of Clinical Endocrinology and Metabolism 64 1194-1198. (doi:10.1210/jcem-64-6-1194)

Cabrera MS, Vogiatzi MG \& New MI 2001 Long term outcome in adult males with classic congenital adrenal hyperplasia. Journal of Clinical Endocrinology and Metabolism 86 3070-3078. (doi:10.1210/jc.86.7.3070)

Couse JF \& Korach KS 1999 Estrogen receptor null mice: what have we learned and where will they lead us? Endocrine Reviews 20 358-417. (doi:10.1210/er.20.3.358)

Curtis SH \& Korach KS 2000 Steroid receptor knockout models: phenotypes and responses illustrate interactions between receptor signaling pathways in vivo. Advances in Pharmacology 47 357-380. (doi:10.1016/S10543589(08)60117-9)

Davidson JM, Chen JJ, Crapo L, Gray GD, Greenleaf WJ \& Catania JA 1983 Hormonal changes and sexual function in aging men. Journal of Clinical Endocrinology and Metabolism 57 71-77. (doi:10.1210/jcem-57-1-71)

Dumesic DA, Schramm RD \& Abbott DH 2005 Early origins of polycystic ovary syndrome. Reproduction, Fertility, and Development 17 349-360. (doi:10.1071/RD04092)

Eddy EM, Washburn TF, Bunch DO, Goulding EH, Gladen BC, Lubahn DB \& Korach KS 1996 Targeted disruption of the estrogen receptor gene in male mice causes alteration of spermatogenesis and infertility. Endocrinology 137 4796-4805. (doi:10.1210/en.137.11.4796)

Forest MG, Nicolino M, David M \& Morel Y 2004 The virilized female: endocrine background. BJU International 93 (Supplement 3) 35-43. (doi:10.1111/j.1464-410X.2004.04707.x)

Hewitt SC \& Korach KS 2003 Oestrogen receptor knockout mice: roles for oestrogen receptors alpha and beta in reproductive tissues. Reproduction 125 143-149. (doi:10.1530/rep.0.1250143)

Hochereau-de Reviers MT, Land RB, Perreau C \& Thompson R 1984 Effect of season of birth and of hemicastration on the histology of the testis of 6-month-old lambs. Journal of Reproduction and Fertility 70 157-163. (doi:10.1530/jrf.0.0700157)
Kosco MS, Loseth KJ \& Crabo BG 1989 Development of the testicular interstitium after neonatal hemicastration in the boar. Journal of Reproduction and Fertility 87 13-21. (doi:10.1530/jrf.0.0870013)

Manikkam M, Crespi EJ, Doop DD, Herkimer C, Lee JS, Yu S, Brown MB, Foster DL \& Padmanabhan V 2004 Fetal programming: prenatal testosterone excess leads to fetal growth retardation and postnatal catch-up growth in sheep. Endocrinology 145 790-798. (doi:10.1210/ en.2003-0478)

Masek KS, Wood RI \& Foster DL 1999 Prenatal dihydrotestosterone differentially masculinizes tonic and surge modes of luteinizing hormone secretion in sheep. Endocrinology 140 3459-3466. (doi:10.1210/en. 140.8.3459)

Matsumoto T, Takeyama K, Sato T \& Kato S 2005 Study of androgen receptor functions by genetic models. Journal of Biochemistry $\mathbf{1 3 8}$ 105-110. (doi:10.1093/jb/mvi118)

Meisel RL \& Ward IL 1981 Fetal female rats are masculinized by male littermates located caudally in the uterus. Science 213 239-242. (doi:10. 1126/science.7244634)

Nachtigall LB, Boepple PA, Pralong FP \& Crowley WF Jr 1997 Adult-onset idiopathic hypogonadotropic hypogonadism - a treatable form of male infertility. New England Journal of Medicine 336 410-415. (doi:10.1056/ NEJM199702063360604)

Orth JM 1984 The role of follicle-stimulating hormone in controlling Sertoli cell proliferation in testes of fetal rats. Endocrinology 115 1248-1255. (doi:10.1210/endo-115-4-1248)

Padmanabhan V, Manikkam M, Recabarren S \& Foster D 2006 Prenatal testosterone excess programs reproductive and metabolic dysfunction in the female. Molecular and Cellular Endocrinology 246 165-174. (doi:10.1016/j.mce.2005.11.016)

Randall VA 1994 Role of 5 alpha-reductase in health and disease. Baillière's Clinical Endocrinology and Metabolism 8 405-431. (doi:10.1016/ S0950-351X(05)80259-9)

Recabarren SE, Lobos A, Figueroa Y, Padmanabhan V, Foster DL \& Sir-Petermann T 2007 Prenatal testosterone treatment alters $\mathrm{LH}$ and testosterone responsiveness to $\mathrm{GnRH}$ agonist in male sheep. Biological Research 40 329-338. (doi:10.4067/S0716-97602007000400007)

Recabarren SE, Rojas-Garcia PP, Recabarren MP, Alfaro VH, Smith R, Padmanabhan V \& Sir-Petermann T 2008 Prenatal testosterone excess reduces sperm count and motility. Endocrinology $1496444-6448$. (doi:10.1210/en.2008-0785)

Resko JA \& Roselli CE 1997 Prenatal hormones organize sex differences of the neuroendocrine reproductive system: observations on guinea pigs and nonhuman primates. Cellular and Molecular Neurobiology 17 627-648. (doi:10.1023/A:1022534019718)

Robertson KM, O'Donnell L, Jones ME, Meachem SJ, Boon WC, Fisher CR, Graves KH, McLachlan RI \& Simpson ER 1999 Impairment of spermatogenesis in mice lacking a functional aromatase (cyp 19) gene. PNAS 96 7986-7991. (doi:10.1073/pnas.96.14.7986)

Ryan BC \& Vandenbergh JG 2002 Intrauterine position effects. Neuroscience and Biobehavioral Reviews 26 665-678. (doi:10.1016/ S0149-7634(02)00038-6)

Sarma HN, Manikkam M, Herkimer C, Dell'Orco J, Welch KB, Foster DL \& Padmanabhan V 2005 Fetal programming: excess prenatal testosterone reduces postnatal luteinizing hormone, but not follicle-stimulating hormone responsiveness, to estradiol negative feedback in the female. Endocrinology 146 4281-4291. (doi:10.1210/en.2005-0322)

Steckler TL, Roberts EK, Doop DD, Lee TM \& Padmanabhan V 2007 Developmental programming in sheep: administration of testosterone during 60-90 days of pregnancy reduces breeding success and pregnancy outcome. Theriogenology 67 459-467. (doi:10.1016/ j.theriogenology.2006.08.010)

Stikkelbroeck NM, Otten BJ, Pasic A, Jager GJ, Sweep CG, Noordam K \& Hermus AR 2001 High prevalence of testicular adrenal rest tumors, impaired spermatogenesis, and Leydig cell failure in adolescent and adult males with congenital adrenal hyperplasia. Journal of Clinical Endocrinology and Metabolism 86 5721-5728. (doi:10.1210/jc.86.12. 5721)

Veiga-Lopez A, Steckler TL, Abbott DH, Welch KB, MohanKumar PS, Phillips DJ, Refsal K \& Padmanabhan V 2011 Developmental programming: impact of excess prenatal testosterone on intra-uterine fetal endocrine milieu and growth in sheep. Biology of Reproduction $\mathbf{8 4}$ 87-96. (doi:10.1095/biolreprod.110.086686) 
Voglmayr JK \& Mattner PE 1968 Compensatory hypertrophy in the remaining tests following unilateral orchidectomy in the adult ram. Journal of Reproduction and Fertility 17 179-181. (doi:10.1530/jrf.0. 0170179)

Waites GM, Wenstrom JC, Crabo BG \& Hamilton DW 1983 Rapid compensatory hypertrophy of the lamb testis after neonatal hemiorchidectomy: endocrine and light microscopical morphometric analyses. Endocrinology 112 2159-2167. (doi:10.1210/endo-112-6-2159)

Waites GM, Speight AC \& Jenkins N 1985 The functional maturation of the Sertoli cell and Leydig cell in the mammalian testis. Journal of Reproduction and Fertility 75 317-326. (doi:10.1530/jrf.0.0750317)

Wilson JD, Griffin JE \& Russell DW 1993 Steroid 5 alpha-reductase 2 deficiency. Endocrine Reviews 14 577-593. (doi:10.1210/edrv-14-5577)
Wolf CJ, Hotchkiss A, Ostby JS, LeBlanc GA \& Gray LE Jr 2002 Effects of prenatal testosterone propionate on the sexual development of male and female rats: a dose-response study. Toxicological Sciences 65 71-86. (doi:10.1093/toxsci/65.1.71)

Zaneveld LJ 1978 The biology of human spermatozoa. Obstetrics and Gynecology Annual 7 15-40.

Received 5 May 2010

First decision 23 June 2010

Revised manuscript received 21 March 2011

Accepted 14 April 2011 